\title{
STERILIZATION OF SYRINGES BY INFRA-RED RADIATION
}

\author{
BY \\ E. M. DARMADY, K. E. A. HUGHES, AND W. TUKE \\ From the Portsmouth and Isle of Wight Area Pathological Service and Public Health Laboratory Service, \\ Portsmouth
}

(RECEIVED FOR PUblication AUGUST 2, 1957)

The introduction of sterile syringe services into hospitals in Britain has focused attention on the inadequacies of the present methods of sterilization. Hitherto the normal practice has been to use either steam sterilizers or hot air ovens. The principal disadvantage of the former is that they are expensive to install, and their present design leaves much to be desired (Bowie, 1955). Furthermore, syringes cannot be sterilized assembled or lubricated, and the syringe containers, whether multiple or single, must be so constructed that steam can freely penetrate to all surfaces of the syringe (Stewart, 1957; Darmady and Hughes, 1955). After sterilization a separate process is necessary to seal the containers before distribution to the user.

Although syringes in their containers can be sterilized presealed in a hot air oven, a hot air oven also has its disadvantages. In a previous communication (Darmady and Brock, 1954), it was shown that many hot air ovens at present manufactured show considerable variation of temperature from one part of the oven to another, and that even distribution of heat can be achieved by a fan. Even then the "load" must be limited and carefully arranged. Another difficulty is that the time taken to reach the sterilizing temperature (usually considered to be $160^{\circ}$ C.) is lengthy, and in most instances is about 50 minutes. To ensure sterilization, a further holding time of half an hour to an hour is necessary, the total process taking a minimum of 80 minutes. Such a time may seriously interfere with the smooth flow of work, and may necessitate a number of hot air ovens. For these reasons it was decided to search for a form of sterilization which would fulfil as far as possible all the necessary criteria. These are:

(1) That all articles should be sterilized ready assembled 'in presealed containers.

(2) That all the articles should reach the sterilization temperature in the shortest possible time.
(3) That all articles should receive the same treatment.

(4) That the sterilization process should be of simple operation and continuous in action.

\section{Construction of the Apparatus}

The apparatus consists of a metal moving belt designed to move at 4 in. a minute (Fig. 1). (This speed was selected as the result of time and motion studies by Brigadier Welch, of the Nuffield Provincial Hospitals Trust, as being the optimum time necessary for an orderly to fill and load a tray with syringes.) The syringes were placed in single layers on trays which were constructed of galvanized sheet metal of a pattern normally used for baking in the hospital kitchen and were therefore robust and cheap. They measured 17 by 11 by $1 \frac{1}{2}$ in.

As soon as the trays were loaded they were placed on the moving belt, and then passed into an insulated tunnel over which " infra-red" projectors were placed at predetermined positions. For this investigation it was decided to use projectors that were available commercially. The projector consists of three elements surrounded on one side by a convex, highly polished metal reflector. Such projectors have either a $4 \mathrm{KW}$. or a $2 \mathrm{KW}$. load, and are fitted with regulators to supply a high, medium, or low output of heat. They were placed at right angles over the moving belt. Four in all were used; the first two ensured that the syringes were brought to the sterilizing temperature, and the remaining two that the temperature was maintained for the requisite period of time. Before the apparatus could be put into routine use, a number of investigations were necessary.

\section{Heating-up Time}

The time taken for the syringes and containers to attain the sterilizing temperature was first considered. For this purpose, a $2 \mathrm{KW}$. projector was placed 4 in. above the bench. The assembled syringes in various containers, into which a thermocouple had been placed, were exposed under the centre of the projector, and readings obtained at half-minute intervals. (The method of preparing a syringe and container for thermocouple readings is described later.) 


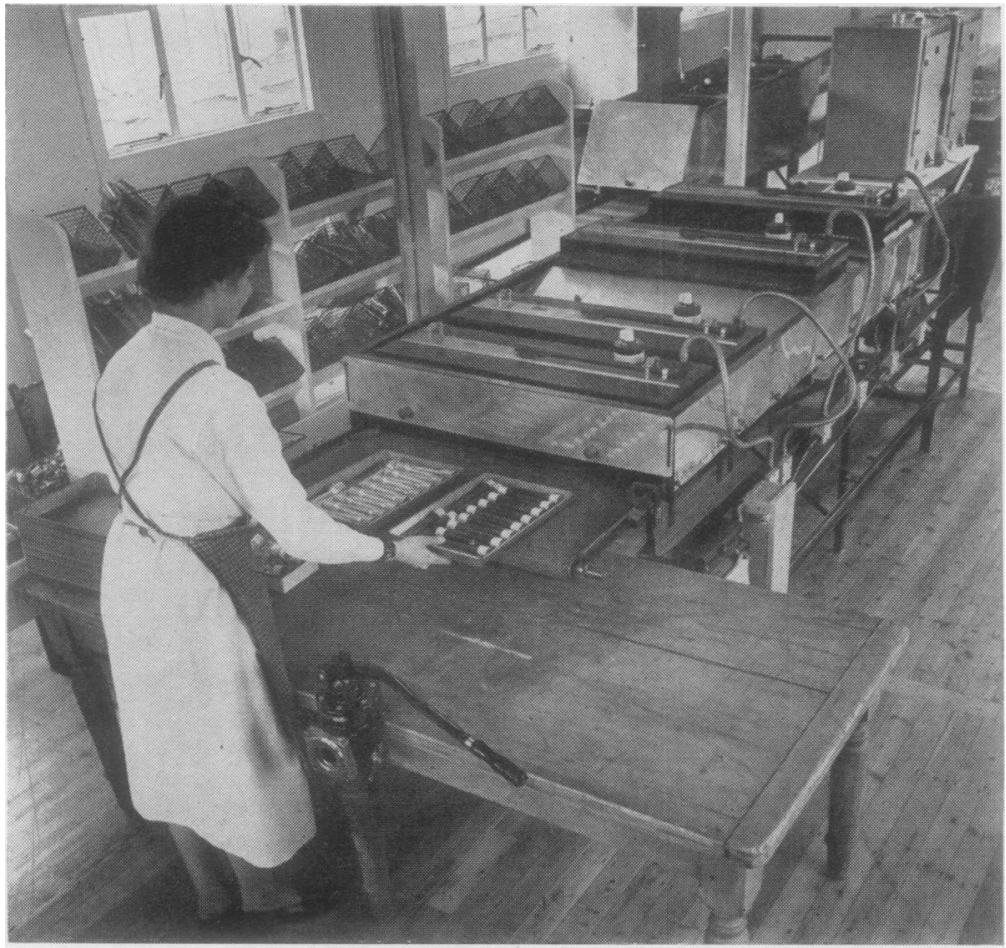

FIG. 1.-A general view of the infra-red moving belt sterilizer in use. A syringe orderly is placing the trays of syringes in presealed containers on the moving belt before sterilization.

The results are shown in Fig. 2. It is seen that a $2 \mathrm{ml}$. syringe placed in a pyrex test tube reached $180^{\circ} \mathrm{C}$. in approximately three minutes after being placed under the projector, whereas a syringe in a dull black, anodized container of the London Hospital pattern took between three and a half and four minutes, and a syringe in a dull, aluminium Nuffield container approximately four and a half minutes.

A $20 \mathrm{ml}$. syringe in a pyrex glass container took approximately four minutes, in an anodized, dull black London Hospital or Nuffield container approximately five minutes, and in a highly polished, black container six and a half minutes. These results therefore indicated that the choice and type of surface of the container were of importance.

\section{Choice of Containers}

Although a glass test tube used as a container allows syringes and needles to be seen, there are certain disadvantages in the use of glass. First, glass is liable to break, and constitutes a severe hazard to the operator ; second, the cost of replacement of glass test tubes is high. (At one time in our Service this amounted to $£ 26$ a month.) Furthermore, it is clear that the apparatus must ensure that the largest article. i.e., a $20 \mathrm{ml}$. syringe, receives adequate heat treatment. This of course inevitably leads to overheating of the small articles, such as $2 \mathrm{ml}$. syringes. To overcome this, it was decided that $2 \mathrm{ml}$. syringes should b@ packed in dull, aluminium containers, and $20 \mathrm{~m} \overrightarrow{5}$ syringes should be packed in aluminium container $\overline{3}$ painted dull black, thus ensuring that the $2 \mathrm{ml}$. and $20 \mathrm{ml}$. syringes reached similar temperatures in the same period of time. This obviates the need to alte. the heat output for different sizes of syringe.

\section{Position of Projectors}

It was, however, also clear that two infra-red heaters were necessary to ensure heat for the first six minutes of the syringes' passage through the tunnel. Foo convenience the two projectors, each 12 in. wide, were placed 2 in. apart giving some overlap of heat, anter providing six and a half minutes' exposure to heat.

\section{Maintenance of Sterilizing Temperature}

Soon after the initial experiments had been con cluded, it was noted that, when syringes in metal confw tainers were withdrawn from the effects of radiatio the temperature in the syringe continued to rise. The reason for this was not clear, but it was thought t $\bar{\varnothing}$ be due to the heat exchange between the cooling outer metal case and the syringes. However, to pre vent overheating it was found by experiments thas with suitable insulation of the tunnel the temperature did not start to fall until the syringes had travelles

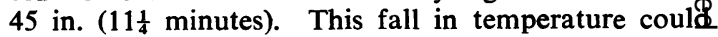




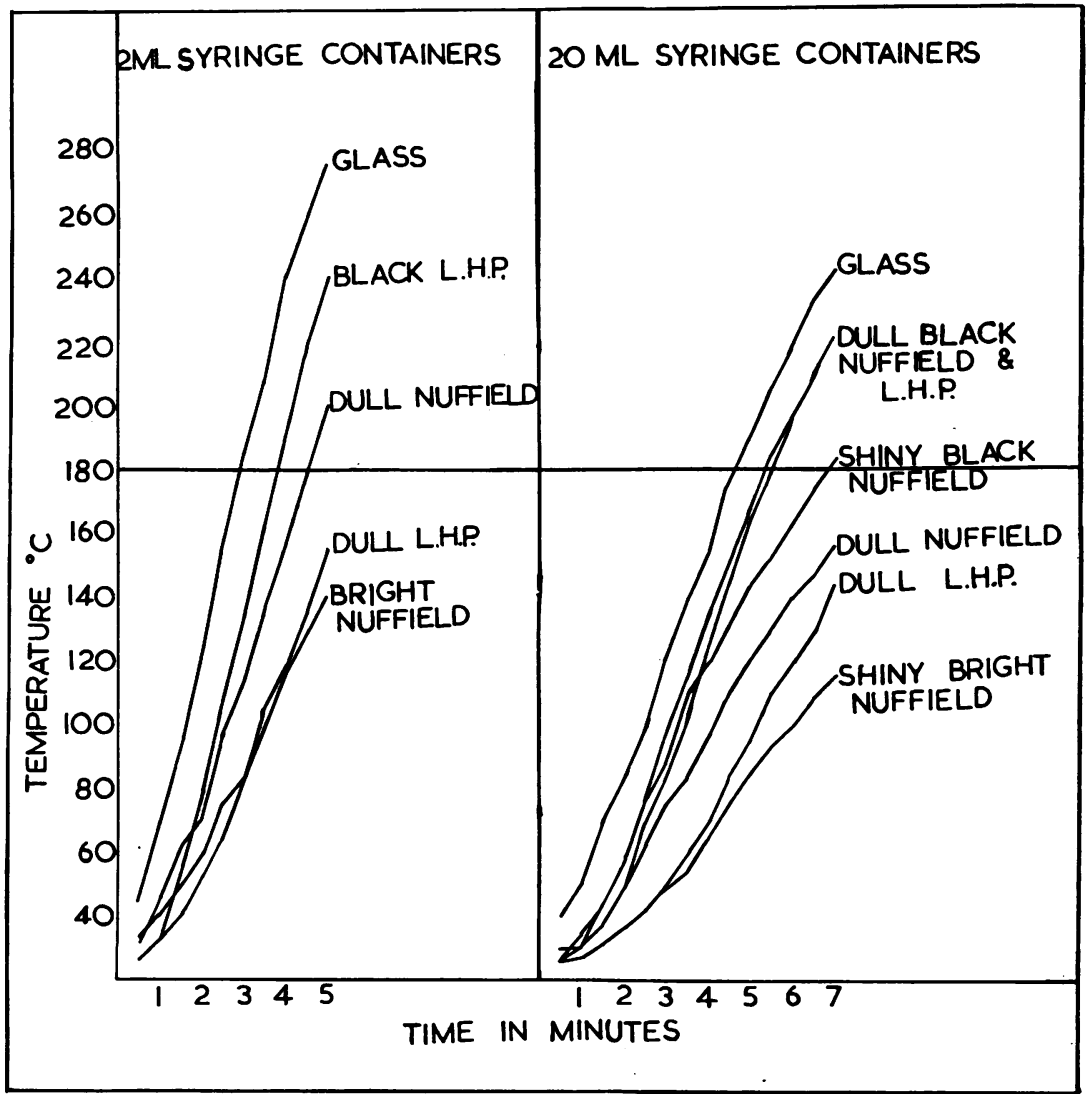

FIG. 2.-Temperature recordings of $2 \mathrm{ml}$. and $20 \mathrm{ml}$. Chance interchangeable syringes placed in varying types of containers exposed to an infra-red projector show different rates of heat taken up. It is noticeable that heat is taken up much more quickly in glass, while syringes in bright shiny aluminium containers were greatly delayed. Painting the aluminium containers with a dull matt black paint greatly improves their ability to take up heat. The heat taken up by $2 \mathrm{ml}$. syringes in dull Nuffield pattern containers is comparable with the performance of $20 \mathrm{ml}$. syringes in matt black containers of either the London Hospital pattern or the Nuffield type. Glass=Pyrex glass test tube. L.H.P.= London Hospital pattern container of spun aluminium. Nuffield $=$ Nuffield pattern container of extruded aluminium. The prefix " dull " implies that the container has been boiled in soda to produce a matt finish. The prefix " black" implies that the container has been painted with matt black heat-resisting paint. The prefix "shiny black" implies that the container has been treated with glossy black heat-resisting stove enamel paint.

be counteracted if a third 12-in. projector was placed at a slightly higher level $(7 \mathrm{in}$.) above the moving belt. At $72 \frac{1}{2}$ in. (18 minutes) from the entrance to the tunnel there was a fall in temperature and a fourth projector was found necessary. As this was sited near the exit a rather higher heat output was required. With these syringe containers a tunnel 89 in. (22⿺ minutes) in length was found to be necessary.

\section{Temperature Variation}

When "infra-red" is used as a heat source variations in temperature sometimes occur. These may be due to alterations either in mains voltage or in the elements themselves.
In this machine it was not possible to stabilize the mains voltage, although it is understood that the heat output varies with the square of the voltage. Although the variation of heat may appear formidable, this can easily be overcome either by fitting a mains voltage stabilizer, or by controlling each element thermostatically.

The use of a tray with a single layer of containers and syringes placed on a moving belt of constant speed ensures that each article receives the same heat treatment. Figs. 3 and 4 show the temperature recordings of various types of $2 \mathrm{ml}$. and $20 \mathrm{ml}$. syringes placed in the same type of containers and placed on the same tray during its passage through the tunnel. It is noticeable that, in spite of a variation in type, 


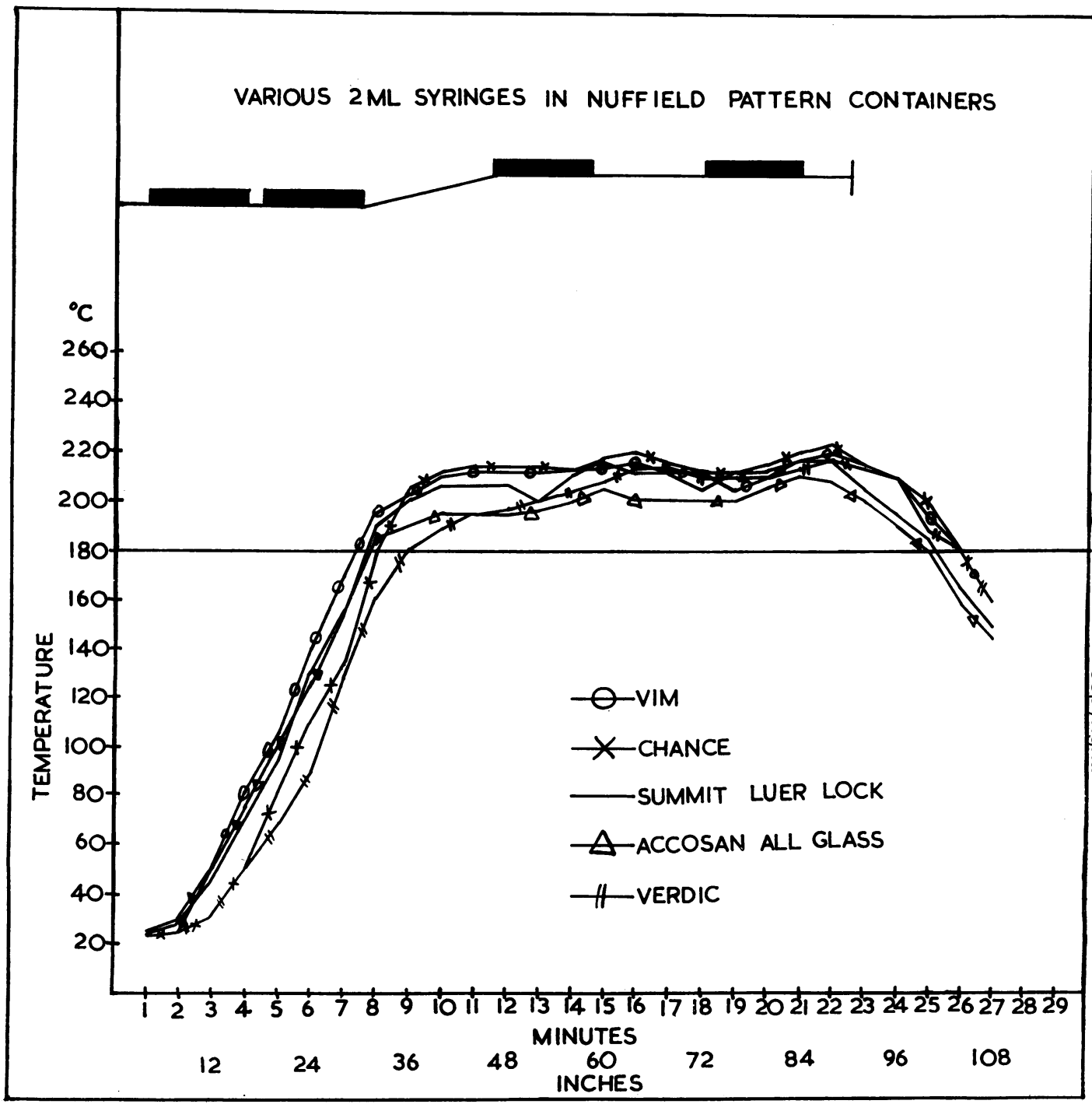

FIG. 3.-Various kinds of $2 \mathrm{ml}$. syringes were exposed in the same type of containers side by side on a metal tray to the moving belt infra-red sterilizer. It is seen that all syringes received a minimum temperature of $180^{\circ} \mathrm{C}$. for at least 16 minutes, and that after heat stabilization the variations of temperature did not exceed $15^{\circ} \mathrm{C}$.

all the $2 \mathrm{ml}$. syringes reached a temperature of $180^{\circ} \mathrm{C}$. within 90 seconds of each other, that the maximum heat variation was less than $14^{\circ} \mathrm{C}$, , that all the syringes exceeded the minimum sterilizing temperature permissible, and that all were subjected to the same heat source for the same period of time ( \pm 2 minutes). With the exception of the "vim" syringe, which has a highly polished metal nozzle, all those of $20 \mathrm{ml}$. size packed in the same type of container reached $180^{\circ} \mathrm{C}$. within 90 seconds of each other. The variation of temperature was less than $10^{\circ} \mathrm{C}$. and was maintained above the minimum sterilizing temperature, though this was lower than that reached by the $2 \mathrm{ml}$. syringes during the same period of time ( \pm 90 seconds). ${ }^{*}$ These results compared more than favourably with those $\mathscr{S}$ obtained in hot air ovens even when fitted with a fan. N It is noticeable that, although the $20 \mathrm{ml}$. syringes did not reach the sterilizing temperature as quickly as the $2 \mathrm{ml}$. syringes, their fall in temperature at the exit of the tunnel was rather longer.

It should be added that in some preliminary investigations the temperature dropped at the edge of the belt, and for this reason temperature measurements

*It was clear that for the "vim" syringe the projectors would have to be placed at lower levels to ensure a slightly higher output of heat. 


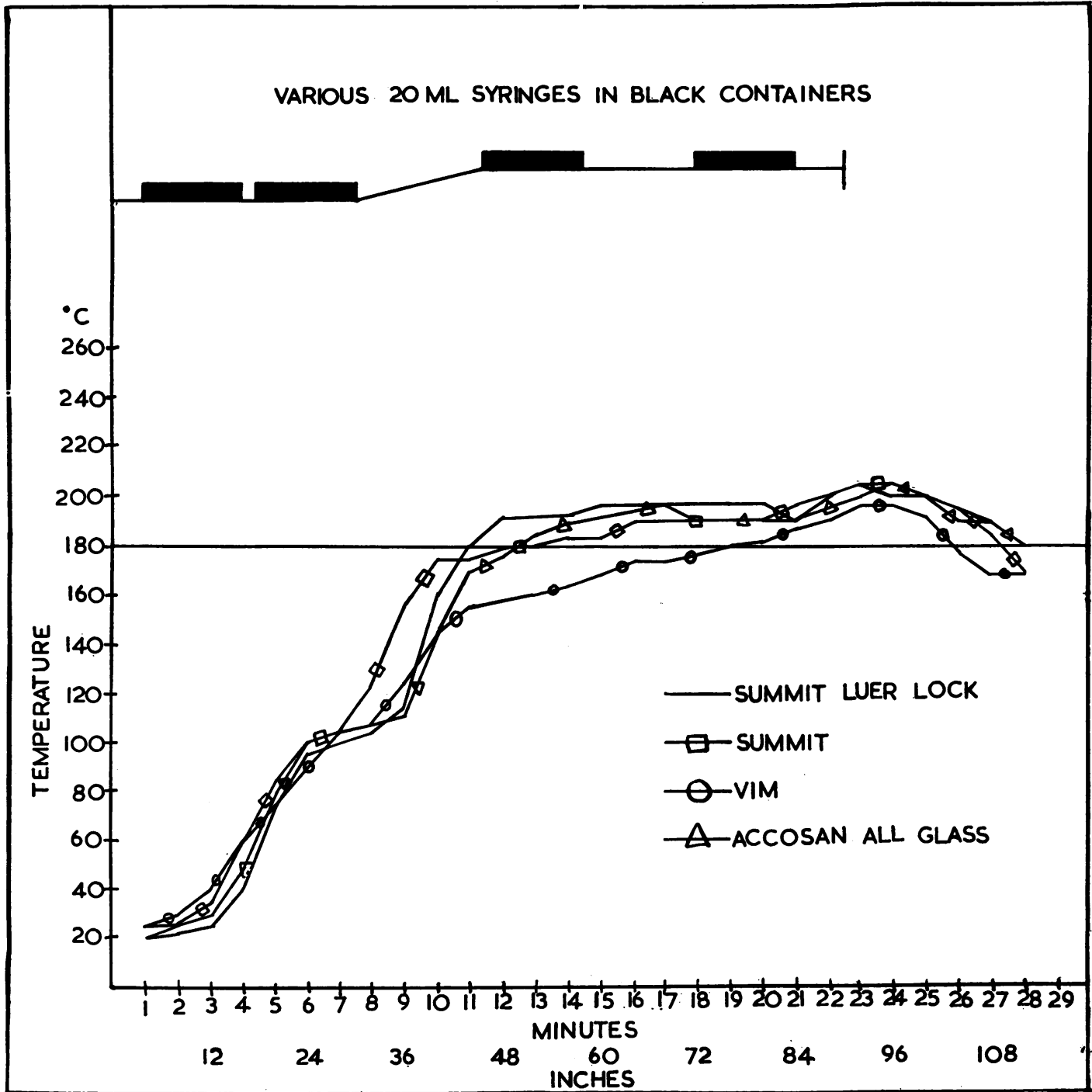

Fig. 4.-Various $20 \mathrm{ml}$. syringes were placed in the same type of containers on a standard tray, and submitted to the moving belt sterilizer. It is noticed that with exception of the "vim" syringe, which has a highly polished nozzle, all the syringes received a temperature of $180^{\circ} \mathrm{C}$. or more for a period of 15 minutes and that the variation of temperature did not exceed $10^{\circ} \mathrm{C}$. after heat stabilization.

were taken in the central portion of the belt, as only this part was used for sterilization. (This is being overcome in the design of the new machines by ensuring that the projectors exceed the width of the belt, and the sides are adequately lagged.)

\section{Thermocouple and Bacteriological Tests}

In order to test the sterilizing ability of the machine bacteriological tests were carried out in conjunction with thermocouple readings. The procedure was to replace the plunger by a test tube containing about
0.1 g. of dried spore-bearing earth supplied by Dr. B. Lacey, of the Westminster Hospital. The syringe and dummy plunger were placed in a container and sealed in a manner similar to routine practice. The thermocouples were of the type recommended in B.S.I. No. 2648:1955 for the testing of drying ovens, and were connected by long leads to a multiple point recorder of the direct reading pattern $\left(5^{\circ} \mathrm{C}\right.$. interval). The metal ball of the thermocouple was passed into the plunger so that it was in direct contact with the internal surface. The plungers were specially drilled or 
had their ends removed. The syringe was then placed in its container and sealed.

The assembled syringes and containers, either attached to a thermocouple or with a test tube of dried earth. were placed side by side on a metal tra! loaded with its full complement of syringes. Usually two or three readings were obtained from the same tray. The loaded tray was placed on the moving helt. and. as soon as it had entered the tunnel. readings were taken at minute intervals timed by a stopwatch.

The comparison of the length of time the syringe was held at given temperatures was compared with the bacteriological results. It is of course true that the temperature reached by the syringe containing a thermocouple may not be identical with that containing the dried earth. The thermocouple. however. was placed inside the plunger to provide an extra margin of safety. since it is clear that the temperature of the cavity within the barrel was certainly higher than that recorded in the plunger.
After the syringes were processed. the tube contain ing the spores was removed. Its contents were divide $B$. in about equal proportions between a tube of diger broth and another of Robertson's cooked mais medium. These were incubated for 48 hours a 37 C.. and subcultured on to blood agar. The sub을 culture from the broth tube was incubated aerobi- $\rightarrow$ cally and from the Robertson s tube anaerobically fol 24 hours at 37 C. No growth on either was taken tho mean that the spores had been hilled.

Subculture on to solid media appears to be im 0 portant. as growth was sometimes obtained from what visualls appeared to be a clear sterile fluid. The lag period for spores which have been heated nearle to death point is longer than for those not so treateve No attempt was made to identify the organism的 concerned.

\section{Bacteriological Results}

Although independent temperature reading $\mathbb{\mathbb { D }}$ and bacteriological tests have been done nid 
very many occasions, comparisons between the two were made 128 times. For some of these investigations the projectors were deliberately altered to give either too high or too low temperatures. The total duration of exposure to heat was always $22 \frac{1}{2}$ minutes. The results obtained can be divided into three groups: (1) When the temperature at no time exceeded $160^{\circ}$ C. ; (2) when the temperature exceeded $160^{\circ}$ C. but not $180^{\circ}$ C.; and (3) when the temperature reached $180^{\circ} \mathrm{C}$. or more for varying periods.

In the first group 10 observations were made; in nine of these the syringes were not sterilized. It was clear, therefore, that it was essential for the temperature to exceed $160^{\circ} \mathrm{C}$. In the second group, equivocal results were obtained, for in a series of 35 observations sterility was recorded in only 21 . There did not appear to be any direct relation between the length of time and the temperature reached on the one hand, and the bacteriological results on the other. This may have been due to slight variations in the amount of dried earth used as the test organisms; for this reason we concluded that the temperature should exceed $180^{\circ} \mathrm{C}$.

TABLE I

HEAT EXPOSURE FOR $22 \frac{1}{2}$ MINUTES AT A TEMPERATURE OF $180^{\circ}$ C. OR MORE

\begin{tabular}{c|c|c}
\hline $\begin{array}{c}\text { Minutes of Exposure } \\
\text { at } 180^{\circ} \text { C. or More }\end{array}$ & Sterile & $\begin{array}{c}\text { No. of } \\
\text { Tests }\end{array}$ \\
\hline 1 & 3 & 4 \\
2 & 3 & 3 \\
3 & 6 & 8 \\
4 & 3 & 3 \\
5 & 5 & 5 \\
6 & 1 & 3 \\
7 & 4 & 5 \\
8 & 3 & 3 \\
9 & 6 & 6 \\
10 & 3 & 3 \\
11 & 8 & 8 \\
12 & 3 & 3 \\
13 & 8 & 8 \\
14 & 3 & 3 \\
15 & 5 & 5 \\
16 & 2 & 2 \\
17 & 4 & 4 \\
18 & 6 & 6 \\
19 & 3 & 3 \\
\hline
\end{tabular}

In the third group the total duration of exposure to heat was $22 \frac{1}{2}$ minutes, during which the temperature recorded always rose to $180^{\circ} \mathrm{C}$. or higher, and occasionally $210^{\circ} \mathrm{C}$. The results are shown in Table I. - In all 87 results were obtained. They showed that when the temperature exceeded $180^{\circ}$ C. for more than seven minutes sterility resulted. Only six positive cultures were obtained, one at a one-minute exposure, two at a three-minute, two at a six-minute, and one at a seven-minute exposure.

\section{Discussion}

At the beginning of this communication we laid down four criteria for successful sterilization practice. We believe that the four criteria have been very largely fulfilled.

Presealing of containers ensures that sterilization of the syringes can be maintained over long periods of time, and radiant heat provided by this method is sufficient to ensure sterility, even when one of the most resistant forms of spores is used. Furthermore, the reduced "heating-up" time has shown that in practice no damage to the syringe has resulted. The use of dull black aluminium containers has ensured that the larger syringes have received the same exposure to heat as the small syringes. It should be emphasized that the machine used was a prototype constructed from apparatus readily available commercially, and not specifically designed for this purpose. Even so, the variation of heat from one syringe to another was considerably less than that in the normal hot air oven at present in use. Furthermore, the machine ensures that all the syringes receive the minimum heat necessary for sterilization, and, as it is in continuous action, it cannot be overloaded.

Properly designed machines fitted with voltage stabilizers and thermostatically controlled elements would not appear to present difficulties, and indeed manufacturers have already placed such machines on the market. The principal difficulty seems to be that so far no authoritative body has yet laid down a standard organism for test purposes, and therefore the actual temperature and the length of time necessary is still a subject of debate. Since the spores in the dried earth were very heat resistant, it seems probable from the figures obtained that a temperature of $180^{\circ} \mathrm{C}$. or more for 11 minutes is adequate to ensure destruction of all the known organisms pathogenic to man. (It is hoped that the results will be the subject of a further communication.)

The fact that syringes and containers are put in single layers on trays which are placed on the moving belt ensures that the sterilizing procedure is simple. Once the loaded tray passes into the tunnel, the operator cannot tamper or prevent the sterilizing process from being carried out in full.

This apparatus has now been in routine use for the past 24 months; no major mechanical faults have developed, and the elements have not required renewal. It is possible that a device to show whether any element is defective might be an added precaution.

In practice the reduction of time necessary for sterilization has reduced the electricity consump- 
tion, and thus has saved money. The apparatus could no doubt be used for the sterilization of many other articles, particularly glassware, but might require modifications to its final design ; the position of the projectors, for example, might require resetting.

It is probable that the ultimate cost of such a machine would be no greater than that of the necessary hot air ovens. The simplicity of its operation would allow less skilled operators to work it, and still ensure sterility, which is not always obtained in a hot air oven.

\section{Summary}

A moving belt infra-red sterilizer for syringes has proved simple to operate; it reduces the "heating-up" time, and allows the syringes to be presealed in their containers before sterilization.

In practice a sterilizing temperature of more than $180^{\circ} \mathrm{C}$. for 11 minutes ensures sterility, and a minimum sterilization temperature can be obtained in all the syringes submitted to the machine as measured by multipoint thermocouples.

To ensure that large and small syringes are heated to the same extent, the large syringes are put into matt black containers which heat up more rapidly, and the small syringes into dull aluminium containers which heat up more slowly. $\stackrel{\stackrel{0}{\vec{\sigma}}}{\underline{\underline{0}}}$

A rigid technique for bacteriological control by both aerobic and anaerobic culture is laid down. $\stackrel{5}{\rightarrow}$ The importance of subculture on to solid media음 from apparently clear, sterile fluid is stressed.

The apparatus used in this investigation was pro- $\vec{\Phi}$ vided from funds of the South-west Metropolitan Regional Hospital Board, and constructed by Messrs. George Vokes Limited, High Road, New Southgate. $\overrightarrow{0}$ London, N.11. We are grateful to A. W. Chalkley. Esq., director of this firm, for his co-operation and $\vec{\omega}$ assistance.

We also wish to thank the Trustees of the Nuffieldo Provincial Hospitals Trust for the loan of the thermo- $\vec{O}$ couples and temperature-measuring apparatus, and for $\rightarrow$ the help given by Miss G. Sellars, who carried out i some of the temperature recordings.

We also acknowledge with thanks the chance re- $ᄋ$ mark of A. C. Townson, Esq., who first suggested the use of infra-red as a heating medium to us.

We are grateful to Dr. B. Lacey, of the Westminster Hospital, for his supply of dried earth used in the bacteriological tests.

\section{REFERENCES}

Bowie, J. H. (1955). Pharm. J., 174, 473. Darmady, E. M., and Brock, R. B. (1954). J. clin. Path. 7, 2900 — and Hughes, K. E. (1955). Lancet, 1, 513.

Stewart, P. D. (1957). J. roy. Army med. Cps, 103, 33 